\title{
Attitudes of pregnant women towards participation in perinatal epidemiological research
}

\author{
Sarah Nechutaa ${ }^{a}$ Lanay M. Mudd ${ }^{a, c}$, Lynette Biery ${ }^{a, d}$, Michael R. Elliott ${ }^{e, f}$, James M. Lepkowski ${ }^{e, f}$, Nigel Paneth ${ }^{a, b}$ \\ and the Michigan Alliance for the National Children's Study \\ Departments of ${ }^{a}$ Epidemiology, and ${ }^{b}$ Pediatrics and Human Development, College of Human Medicine, 'Department of Kinesiology, College of \\ Education, and ${ }^{d}$ Institute for Health Care Studies, Michigan State University, East Lansing, MI, ${ }^{e}$ Department of Biostatistics, School of Public \\ Health, and Institute for Social Research, University of Michigan, Ann Arbor, MI, USA
}

\author{
Correspondence: \\ Sarah Nechuta, MPH, \\ Michigan State University, \\ Department of Epidemiology, \\ B601 West Fee Hall, East \\ Lansing, MI 48824, USA. \\ E-mail: \\ snechuta@epi.msu.edu
}

\section{Summary}

Nechuta S, Mudd LM, Biery L, Elliott MR, Lepkowski JM, Paneth N, Michigan Alliance for the National Children's Study. Attitudes of pregnant women towards participation in perinatal epidemiological research. Paediatric and Perinatal Epidemiology 2009; 23: 424-430.

We assessed attitudes of a multi-ethnic sample of pregnant women in regard to participation in five data collection procedures planned for use in the National Children's Study. A cross-sectional survey was conducted in nine prenatal clinics in Kent County, Michigan between April and October 2006. Women were approached in clinic waiting rooms at the time of their first prenatal visit and 311 (91.0\%) participated. Women were asked about their willingness to participate, and the smallest amount of compensation required for participation in a 45-min in-person interview, a 15-min telephone interview, maternal and infant medical record abstraction, and an infant physical examination.

Percentages for willingness to participate were highest for telephone interview $(83 \%)$, followed by in-person interview $(60 \%)$, infant examination $(57 \%)$, and maternal $(56 \%)$ and infant medical records (54\%). About $34-48 \%$ of women reported that no compensation would be required for participation by data procedure. Some women reported unwillingness to participate in telephone $(9 \%)$ or personal $(17 \%)$ interview, record abstraction (34\%) or infant examination (26\%), even with compensation. Education greater than high school was associated with increased odds of refusal for infant physical examination, adjusted odds ratio 2.44 [95\% confidence interval 1.41, 4.23]. In conclusion, $9-34 \%$ of pregnant women, depending on procedure, stated they would not participate in non-invasive research procedures such as medical record abstraction and infant examination, even with compensation. Resistance to these research procedures was especially noted among more highly educated women. Planning for the National Children's Study will have to address potential resistance to research among pregnant women.

Keywords: pilot, National Children's Study, refusal rate, maternal education.

\section{Introduction}

High participation in all components of data collection protocols in epidemiological studies is important for valid study inferences. ${ }^{1}$ Understanding both the feasibility of agreement to participate in data procedures and the role of compensation for participation among different populations may improve study planning, leading to optimal recruitment and retention methods. Pregnant women may have attitudes towards research participation that differ from other populations, possibly due to their health status and/or interest in learning about pregnancy. ${ }^{2}$

While substantial literature exists on hypothetical attitudes towards participation in various types of 
research studies, ${ }^{2-11}$ few studies have focused on observational research during pregnancy and at birth. ${ }^{2,9,10}$ The literature is particularly limited for attitudes concerning willingness to participate in observational research among currently pregnant women. The one study we identified reported only general attitudes of pregnant women towards future prenatal research. ${ }^{10}$

In the light of the paucity of information on attitudes of pregnant women towards participation in observational research, we conducted a cross-sectional survey of attitudes of pregnant women in a multi-ethnic sample in Kent County, Michigan (MI). We assessed attitudes towards participation in five hypothetical data collection procedures planned for use in the National Children's Study (NCS) and the desired compensation for participation in each procedure. We also examined maternal factors associated with unwillingness to participate by data procedure.

\section{Methods}

\section{Michigan Alliance for the National Children's Study-Pilot Study}

The NCS will examine a variety of social, psychological, environmental and biological exposures in relation to child health and development. ${ }^{12}$ Women will be recruited pre-conceptionally and during pregnancy and 100000 children will be followed until 21 years of age. The Michigan Alliance for the National Children's Study (MANCS) was formed in 2002 to promote planning efforts for the NCS in MI. ${ }^{13}$ Recognising the complexity of performing research in pregnant women, MANCS conducted a pilot study to examine attitudes of pregnant women and their health care providers to participation in procedures likely to be used in the NCS. From April-October 2006, in-person interviews of pregnant women were conducted and surveys were distributed to staff in prenatal care clinics and delivery rooms in Kent County. ${ }^{14}$ The study was approved by the Institutional Review Boards of Michigan State University and three hospitals with labour and delivery services in the county.

\section{Study population}

Using data from the Kent County Health Department, 10 prenatal care clinics were sampled based on estimates of the annual number of prenatal patients and the racial/ethnic composition of the population.
Selected practices included private, Medicaid/ Medicare and bilingual (English/Spanish) clinics, as well as one midwifery clinic. Nine clinics allowed the interviewing of pregnant women.

Eligible women were pregnant, aged 18-50 years, making their first prenatal visit, and proficient in English or Spanish. Women at the clinic for their first prenatal visit received a study brochure at check-in, which included a description of the NCS and purpose of the pilot study. Interviewers approached women with a study brochure in clinic waiting rooms, determined eligibility and described the study. During enrolment, we missed 94 new patients because an interviewer was unavailable. We were unable to determine eligibility for these missed women. Among 374 women approached, $32(8.0 \%)$ were found to be ineligible (20 were minors; 10 had a language barrier; 2 were not pregnant). Of the remaining 342 eligible women approached, 311 (91\%) participated.

\section{Data collection}

Interviewers obtained written informed consent and conducted 15-20 min in-person interviews in English or Spanish either before or after appointments. Interviewers described the NCS and pilot study to eligible women. This included an explanation of how the NCS would involve many data collection procedures and that the purpose of the pilot study was to determine willingness to participate in specific parts, so if women were more resistant to a particular procedure, planning efforts for the NCS could be adjusted accordingly. (The complete survey is available from the corresponding author).

Attitudes towards hypothetical participation and compensation for planned procedures were assessed, including: (1) $45 \mathrm{~min}$ in-person interview during a prenatal care clinic visit; (2) 15 min telephone interview during pregnancy; (3) maternal medical record abstraction; (4) infant medical record abstraction; (5) infant physical examination; (6) maternal blood collection; (7) cord blood collection; (8) placenta collection; and (9) biological specimen storage. The first five procedures are the focus of this paper. Attitudes towards collection of biological specimens will be reported in a subsequent manuscript.

Women were first asked their willingness to participate in each procedure (yes, no, it depends). Second, women were asked the smallest amount of monetary compensation they would require to participate in each 
procedure (no compensation required for participation, any dollar amount volunteered, or would not participate for any compensation). Third, women were asked to pick their top choice out of four compensation types (gift cards, free supplies/toys, college fund/savings bond and money). Maternal factors assessed included race/ethnicity, age, education, annual family income, relationship status, parity and gestational week (maternally estimated trimester only if week not known). Women completing the interview received a $\$ 10$ gift card.

\section{Study variables}

We created categorical variables for willingness to participate when compensation attitudes were assessed (would participate if compensated, would participate for no compensation, would not participate for any compensation) and for lowest reported compensation amount by procedure (\$0, $\$ 1-10, \$ 11-20, \$ 21-49$, $\geq \$ 50$ ). We created binary variables for unwillingness to participate by procedure (would not participate for any compensation, would participate for no/some compensation) for use in logistic regression analyses. Categorical variables were created for race/ethnicity, age, education for women $\geq 19$ years of age and annual family income. Binary variables were used to describe relationship status (married: yes, no), parity (primiparous: yes, no) and trimester (first: yes, no).

\section{Analysis}

Frequencies and percentages (and means where appropriate) were calculated for attitudes and maternal factors. Logistic regression was used to examine factors associated with unwillingness to participate (would not participate for any compensation; reference $=$ would participate) by procedure. We evaluated several factors together (race/ethnicity, age, education, income, marital status, parity and trimester) to determine the independent associations with unwillingness to participate in each procedure. Adjusted results include all maternal factors evaluated as potential confounders with some exceptions due to high correlation between covariates and/or lack of precision (see Table 5).

We used PROC GENMOD for logistic regression models to account for clustering by clinic and calculated odds ratios (ORs) and 95\% confidence intervals
[CI]. SAS version 9.1.3 was used for all analyses. $P$-values $<0.05$ indicated statistical significance.

\section{Results}

Table 1 displays participant characteristics. Women ranged in age from 18 to 41 years and close to half reported a family income $<\$ 25000$. Most women were interviewed in English (88\%) and about 6\% reported they were aware of the NCS.

The percentage of women that agreed to hypothetical participation was highest for telephone interview and lowest for maternal or infant medical record review (Table 2). For women who said 'it depends', the percentage was highest for infant physical examination and lowest for telephone interview (Table 2). Slightly more than half would agree to participate in both in-person and telephone interview (53\%), and exactly one-half would participate in both maternal and infant medical record review. Just 70 women $(23 \%)$ would

Table 1. Characteristics of pregnant women, MANCS Pilot Study $(n=311)^{\mathrm{a}}$

$n(\%)$

$\begin{array}{lc}\text { Maternal race } & \\ \text { Non-Hispanic White } & 180(59) \\ \text { Non-Hispanic Black } & 51(17) \\ \text { Hispanic } & 61(20) \\ \text { Non-Hispanic other } & 14(4) \\ \text { Maternal age (years) } & \\ \quad<25 & 109(35) \\ 25-29 & 107(35) \\ 30-34 & 67(22) \\ \geq 35 & 26(8) \\ \text { Annual family income (dollars) } & \\ <25 \text { 000 } & 137(45) \\ 25-49 \text { 999 } & 73(24) \\ \geq 50 \text { 000 } & 96(31) \\ \text { Education (among women } \geq 19) & \\ <\text { High school } & 63(21) \\ \text { High school } & 52(18) \\ \text { Some college } & 87(29) \\ \text { Bachelor's or higher } & 93(32) \\ \text { Married } & 159(52) \\ \text { Primiparous } & 126(41) \\ \text { First trimester } & 245(79) \\ \end{array}$

aFrequencies and percentages exclude missing by characteristic: race/ethnicity $(n=5), \quad$ age $(n=2), \quad$ income $(n=5)$, education $(n=2)$, married $(n=4)$.

MANCS, The Michigan Alliance for the National Children's Study. 
Table 2. Willingness to participate by planned data procedure among pregnant women, MANCS Pilot Study

\begin{tabular}{lccc}
\hline & \multicolumn{3}{c}{ Willingness to participate } \\
\cline { 2 - 4 } & $\begin{array}{c}\text { Yes } \\
n(\%)\end{array}$ & $\begin{array}{c}\text { No } \\
n(\%)\end{array}$ & $\begin{array}{c}\text { It depends } \\
n(\%)\end{array}$ \\
\hline 45 min in-person interview & $179(60)$ & $68(23)$ & $53(18)$ \\
15 min telephone interview & $256(83)$ & $37(12)$ & $16(5)$ \\
$\begin{array}{l}\text { Maternal medical record } \\
\text { abstraction }\end{array}$ & $164(56)$ & $88(30)$ & $42(14)$ \\
$\begin{array}{l}\text { Infant medical record } \\
\text { abstraction }\end{array}$ & $157(54)$ & $84(29)$ & $49(17)$ \\
$\begin{array}{l}\text { Infant physical examination } \\
\text { nany }\end{array}$ & $167(57)$ & $64(22)$ & $62(21)$ \\
\hline
\end{tabular}

${ }^{a}$ Frequencies and percentages exclude missing by procedure: in-person interview $(n=11)$, telephone interview $(n=2)$, maternal medical records $(n=17)$, infant medical records $(n=21)$, infant examination $(n=18)$.

MANCS, The Michigan Alliance for the National Children's Study. agree to all five procedures, while 12 women (4\%) said they would refuse to participate in all procedures.

Table 3 displays willingness to participate when compensation attitudes were assessed. Willingness increased when compensation was offered; however, some women reported they would not participate even with compensation.

Table 4 shows monetary compensation attitudes by data procedure for women who reported they would be willing to participate. The mean amount of monetary compensation was highest for infant examination and lowest for telephone interview. About 52-66\% of women (by procedure) reported they would require compensation for participation. We also asked women to pick their top choice out of four types of compensation. A college fund was preferred by most women (54\%), followed by gift cards (24\%), money (14\%) and free supplies/toys ( $8 \%$ ).

We examined factors associated with unwillingness to participate even with compensation by data procedure (Table 5). In unadjusted models (data not shown),

\begin{tabular}{|c|c|c|c|}
\hline & $\begin{array}{l}\text { Would participate } \\
\text { if compensated } \\
n(\%)\end{array}$ & $\begin{array}{l}\text { Would participate for } \\
\text { no compensation } \\
n(\%)\end{array}$ & $\begin{array}{l}\text { Would not participate for } \\
\text { any compensation } \\
n(\%)\end{array}$ \\
\hline $45 \mathrm{~min}$ in-person interview & $154(54)$ & $80(28)$ & $49(17)$ \\
\hline 15 min telephone interview & $139(48)$ & $126(43)$ & $27(9)$ \\
\hline Medical record abstraction ${ }^{\mathrm{b}}$ & $97(35)$ & $88(32)$ & $93(34)$ \\
\hline Infant physical examination & $109(40)$ & $91(34)$ & $70(26)$ \\
\hline
\end{tabular}

${ }^{a}$ Frequencies and percentages exclude missing by data procedure: in-person interview $(n=28)$, telephone interview $(n=19)$, medical records $(n=33)$, infant examination $(n=41)$.

${ }^{b}$ For compensation questions, maternal medical records and infant medical records were not assessed separately.

MANCS, The Michigan Alliance for the National Children's Study.

\begin{tabular}{llccccc}
\hline & \multicolumn{5}{c}{ Lowest amount of monetary compensation } \\
\cline { 2 - 7 } & & $\$ 0$ & $\$ 1-10$ & $\$ 11-20$ & $\$ 21-49$ & $\geq \$ 50$ \\
& Mean (SE) & $n(\%)$ & $n(\%)$ & $n(\%)$ & $n(\%)$ & $n(\%)$ \\
\hline 45 min in-person interview & $37(2.6)$ & $80(34)$ & $30(13)$ & $47(20)$ & $28(12)$ & $49(21)$ \\
15 min telephone interview & $17(2.2)$ & $126(48)$ & $78(29)$ & $40(15)$ & $15(6)$ & $6(2)$ \\
Medical record abstraction & $45(7.7)$ & $88(48)$ & $29(16)$ & $20(11)$ & $17(9)$ & $31(17)$ \\
Infant physical examination & $57(10.4)$ & $91(46)$ & $17(8)$ & $27(14)$ & $20(10)$ & $45(23)$ \\
\hline
\end{tabular}

${ }^{a}$ Frequencies and percentages exclude missing and women who would not participate for any amount of compensation by procedure.

${ }^{b}$ Means exclude women who reported $\$ 0$ by procedure and 1 woman who reported $\$ 5000$ for each procedure (SE, standard error).

MANCS, The Michigan Alliance for the National Children's Study.
Table 3. Willingness to participate when compensation attitudes were assessed among pregnant women, MANCS Pilot Study ${ }^{a}$

Table 4. Compensation attitudes by planned data procedure among pregnant women who agreed to hypothetical participation, MANCS Pilot Study ${ }^{a}$ 
Table 5. Adjusted odds ratios for unwillingness to participate in planned data procedures even if offered compensation, MANCS Pilot Study

\begin{tabular}{|c|c|c|c|c|}
\hline & $\begin{array}{c}45 \text { min in-person interview } \\
\text { OR }[95 \% \mathrm{CI}]^{\mathrm{b}}\end{array}$ & $\begin{array}{c}15 \text { min telephone interview } \\
\text { OR }[95 \% \mathrm{CI}]^{\mathrm{b}}\end{array}$ & $\begin{array}{c}\text { Medical record abstraction } \\
\text { OR }[95 \% \mathrm{CI}]^{\mathrm{b}}\end{array}$ & $\begin{array}{c}\text { Infant physical examination } \\
\text { OR }[95 \% \mathrm{CI}]^{\mathrm{b}}\end{array}$ \\
\hline \multicolumn{5}{|l|}{ Race/ethnicity ${ }^{\mathrm{C}}$} \\
\hline NH White & 1.00 Reference & 1.00 Reference & 1.00 Reference & 1.00 Reference \\
\hline NH Black & $1.78[0.42,7.45]$ & $2.36[0.81,6.92]$ & $1.83[0.68,4.96]$ & $1.03[0.36,3.01]$ \\
\hline Hispanic & $1.95[0.70,5.40]$ & $2.07[0.61,7.01]$ & $1.78[0.93,3.39]$ & $1.58[0.55,4.56]$ \\
\hline \multicolumn{5}{|l|}{ Maternal age } \\
\hline$<25$ years & $1.51[1.18,1.93]$ & $1.44[0.69,3.03]$ & $1.01[0.60,1.70]$ & $0.87[0.49,1.53]$ \\
\hline$\geq 25$ years & 1.00 Reference & 1.00 Reference & 1.00 Reference & 1.00 Reference \\
\hline \multicolumn{5}{|l|}{ Education $^{\mathrm{d}}$} \\
\hline$<$ High school & 1.00 Reference & 1.00 Reference & 1.00 Reference & 1.00 Reference \\
\hline High school & $0.71[0.26,1.92]$ & $1.45[0.87,2.40]$ & $1.45[0.68,3.08]$ & $0.95[0.38,2.37]$ \\
\hline$>$ High school & $1.03[0.34,3.16]$ & $1.11[0.51,2.42]$ & $2.23[0.97,5.15]$ & $2.44[1.41,4.23]$ \\
\hline \multicolumn{5}{|l|}{ Annual income } \\
\hline$<\$ 25000$ & 1.00 Reference & 1.00 Reference & 1.00 Reference & 1.00 Reference \\
\hline$\geq \$ 25000$ & $0.63[0.24,1.61]$ & $0.80[0.22,2.97]$ & $1.15[0.45,2.96]$ & $0.73[0.29,1.82]$ \\
\hline \multicolumn{5}{|l|}{ Marital status } \\
\hline Married & $1.85[0.65,5.27]$ & $0.91[0.42,1.98]$ & $1.10[0.63,1.90]$ & $1.16[0.74,1.80]$ \\
\hline Not married & 1.00 Reference & 1.00 Reference & 1.00 Reference & 1.00 Reference \\
\hline \multicolumn{5}{|l|}{ Primiparous } \\
\hline Yes & $1.17[0.53,2.57]$ & $1.14[0.63,2.04]$ & $1.17[0.61,2.22]$ & $1.03[0.55,1.92]$ \\
\hline No & 1.00 Reference & 1.00 Reference & 1.00 Reference & 1.00 Reference \\
\hline
\end{tabular}

aTable excludes missing data by procedure. ORs statistically significant at $\alpha \leq 0.05$ level are in bold print.

${ }^{b}$ Adjusted for age, education, marital status, parity and trimester (where appropriate); models where education is the main factor of interest are also adjusted for race/ethnicity.

'Excludes $\mathrm{NH}$ other $(n=14)$.

${ }^{\mathrm{d}}$ Among participants $\geq 19$ years of age.

MANCS, The Michigan Alliance for the National Children's Study; NH, non-Hispanic.

women of younger age $(<25$ years) were less likely to report they would refuse to participate in an infant examination (OR 0.55 [95\% CI 0.32, 0.94]). Women of higher education (> high school) were more likely to report they would refuse to participate in record abstraction (OR 2.46 [95\% CI 1.53, 3.94]) and infant examination (OR 2.72 [95\% CI 1.73, 4.26]), as were married women for record abstraction (OR 1.45 [95\% CI 1.03, 2.04]) and infant examination (OR 1.72 [95\% CI $1.11,2.67])$. After adjustment, only the positive association between higher education and refusal for infant examination remained significant. In addition, in adjusted analyses, younger maternal age was associated with an increased likelihood of refusal for personal interview (Table 5).

\section{Discussion}

This cross-sectional survey provides data on pregnant women's attitudes towards hypothetical research par- ticipation and desired compensation. We found that a majority of pregnant women (54-83\%, depending on procedure) would participate in non-invasive research procedures commonly used in epidemiological studies, such as interviews, record abstraction and examinations. Moreover, $34-48 \%$ of women who would participate would do so without compensation (depending on procedure). However, 9-34\% of women would refuse to participate in such procedures, even with compensation. Resistance was highest for medical records and infant physical examinations. We found evidence for increased resistance to those procedures among women with higher education. Younger women were more likely to resist longer in-person interviews.

The attitudes of pregnant women towards hypothetical participation in observational research during pregnancy and at birth have largely been unexplored. Jorgensen reported that 59\% of Danish pregnant women who accepted or declined an alpha-fetoprotein test would support continued prenatal research. ${ }^{10}$ 
Daniels and colleagues found that the majority of postpartum women who had recently participated in a cohort study of pregnancy reported that they felt comfortable with all study procedures and $80 \%$ said they would be willing to participate in a future study of pregnancy. ${ }^{2}$

In our study of hypothetical attitudes, we were interested in associations between maternal factors and unwillingness to participate, even with compensation. Most maternal factors were not significantly associated with resistance to participation in the five data procedures. We did find, however, that higher education (>high school) was associated with increased resistance to an infant physical examination and possibly to record abstraction. Younger age was associated with increased resistance to in-person interviews. Some studies of attitudes to participation in hypothetical research situations have found differences by education, ${ }^{2}$ while others have not. ${ }^{4,9}$ Daniels and colleagues examined attitudes of mothers towards participation of their children in future research activities and found some evidence that women of higher education were more resistant, although results were very imprecise. ${ }^{2}$

To our knowledge, data on pregnant women's attitudes towards monetary compensation for hypothetical involvement in specific research procedures have not been reported previously. We found that about 34-48\% of pregnant women would not require monetary compensation for participation. This finding fits with previous studies that have found contribution to science and learning about pregnancy to be main motivators for actual participation in studies during pregnancy. ${ }^{2,15}$

Depending on procedure, monetary suggestions were fairly similar to those used in practice for a majority of women (e.g. close to $80 \%$ of women suggested $\$ 0-10$ for a short telephone interview ${ }^{16}$ ); however, about $20 \%$ of women asked for $\$ 50$ or more for participation in personal interviews, medical record review and infant examinations. We also found that when asked to select their top choice of compensation, more women chose a college fund/savings bond or gift cards, rather than money. Although published reports provide important data on motivating factors for actual participation in studies conducted during pregnancy, ${ }^{2,15,17}$ these studies exclude women who did not participate. Our results can inform discussions on the appropriate compensation amounts/types to be used for observational research among pregnant women.

Strengths of our study include: (1) prenatal care clinics sampled to represent a cross-section of the county population and to include clinics serving a variety of ethnic and socio-economic strata; (2) participation of nine out of ten clinics sampled; (3) $>90 \%$ participation rate for eligible pregnant women approached; and (4) inclusion of a high proportion of both non-Hispanic Black and Hispanic women, improving the generalisability of study results to other general populations of pregnant women.

Several study limitations must be noted. Because our study is not population-based, the results may not be generalisable to all pregnant women who received services at prenatal care clinics in Kent County during the enrolment period. We did, however, compare the demographics of our sample to vital statistics data for 2006 livebirths in the county and percentages were similar for most maternal demographics, which suggests our sample is fairly representative. ${ }^{18}$ Second, since our study was conducted in clinics, women's attitudes may have been more positive due to perceived support of the study by their health care providers, although our recruitment methods parallel the way in which some women will be recruited for the NCS. Third, we assessed attitudes for hypothetical situations. Attitudes may change over time and also may not reflect actual behaviour. ${ }^{19,20}$ Another limitation is that we did not collect information on why women reported that they were unsure or unwilling to participate in the research procedures.

Our key finding - that while most women are open to non-invasive medical research in pregnancy, a minority are quite resistant - is an important message for pregnancy research in general, and for the NCS in particular. It is reasonable to expect that when an actual study is presented to pregnant women, its rationale explained in detail, and its commitment to security of data affirmed, participation rates may be higher than found in our survey. Confidentiality of research information is especially important to address, in light of the high levels of resistance we encountered to medical record abstraction. The NCS also plans substantial community engagement efforts in its study locations that should encourage participation. Our results indicate that such efforts will be very important if enrolment in the NCS is to be optimised.

\section{Acknowledgements}

The authors would like to thank the staff members at participating clinics and hospitals for their cooperation, as well as Brian Hartl, Barb Hawkins-Palmer and other 
staff at the Kent County Health Department, the Grand Rapids Medical Education Research Center, and Brian Lamoreaux for assistance in planning and implementing the study.

We would also like to acknowledge the MANCS Steering Committee which included, at the time this study was performed, Jan Bokemeier, Naomi Breslau, H. Dele Davies, and Nigel Paneth from Michigan State University; Valerie Castle, Michael Elliott, Timothy Johnson, Daniel Keating, and James Lepkowski from the University of Michigan; Charles Barone, Christine Johnson, and Christine Joseph from Henry Ford Health System; Virginia Delaney-Black, William Lyman, Hilary Ratner, Robert Sokol, Bonita Stanton, and Daniel Waltz from Wayne State University; Lori Cameron, Violanda Grigorescu, and Doug Paterson from Michigan Department of Community Health, and Health Officers/Medical Directors from Grand Traverse County (Frederick Keeslar), Lenawee County (R. Michael Knight), Genesee County (Robert Pestronk), Macomb County (Kevin Lokar), and Wayne County (Kathy Urbats, Anahid Kulwicki).

Funding for this study was provided by the Henry Ford Health System, Michigan State University, the University of Michigan, and Wayne State University.

\section{References}

1 Schuz J. Non-response bias as a likely cause of the association between young maternal age at the time of delivery and the risk of cancer in the offspring. Paediatric and Perinatal Epidemiology 2003; 17:106-112.

2 Daniels JL, Savitz DA, Bradley C, Dole N, Evenson KR, Eucker B, et al. Attitudes toward participation in a pregnancy and child cohort study. Paediatric and Perinatal Epidemiology 2006; 20:260-266.

3 Trauth JM, Musa D, Siminoff L, Jewell IK, Ricci E. Public attitudes regarding willingness to participate in medical research studies. Journal of Health and Social Policy 2000; 12:23-43.

4 Comis RL, Miller JD, Aldige CR, Krebs L, Stoval E. Public attitudes toward participation in cancer clinical trials. Journal of Clinical Oncology 2003; 21:830-835.

5 Shavers VL, Lynch CF, Burmeister LF. Racial differences in factors that influence the willingness to participate in medical research studies. Annals of Epidemiology 2002; 12:248-256.

6 Katz RV, Kegeles SS, Kressin NR, Green BL, Wang MQ, James SA, et al. The Tuskegee Legacy Project: willingness of minorities to participate in biomedical research. Journal of
Health Care for the Poor and Underserved 2006; 17:698-

715

7 Maayan-Metzger A, Kedem-Friedrich P, Kuint J.

Motivations of mothers to enroll their newborn infants in general clinical research on well-infant care and development. Pediatrics 2008; 121:e590-e596.

8 Rodger MA, Makropoulos D, Walker M, Keely E, Karovitch A, Wells PS. Participation of pregnant women in clinical trials: will they participate and why? American Journal of Perinatology 2003; 20:69-76.

9 Neidich AB, Joseph JW, Ober C, Ross LF. Empirical data about women's attitudes towards a hypothetical pediatric biobank. American Journal of Medical Genetics. Part A 2008; 146:297-304.

10 Jorgensen FS. Attitudes to prenatal screening, diagnosis and research among pregnant women who accept or decline an alpha-fetoprotein test. Prenatal Diagnosis 1995; 15:419-429.

11 Kettis-Lindblad A, Ring L, Viberth E, Hansson MG. Genetic research and donation of tissue samples to biobanks. What do potential sample donors in the Swedish general public think? European Journal of Public Health 2006; 16:433-440.

12 Landrigan PJ, Trasande L, Thorpe LE, Gwynn C, Lioy PJ, D'Alton ME, et al. The National Children's Study: a 21-year prospective study of 100,000 American children. Pediatrics 2006; 118:2173-2186

13 Lyman WD, Barone C, Castle V, Davies HD, Stanton B, Paneth N. Making the National Children's Study a real partnership with academic pediatrics. Journal of Pediatrics 2005; 147:563-564.

14 Mudd LM, Pham X, Nechuta S, Elliott MR, Lepkowski JM, Paneth N. Prenatal care and delivery room staff attitudes toward research and the National Children's Study. Maternal and Child Health Journal 2008; 12:684-691.

15 Lamvu G, Lorenz C, Jonsson Funk M, Makarushka C, Hartmann K, Savitz D. Racial differences among reasons for participating in research of pregnancy outcomes: the right from the start experience. Gender Medicine 2005; 2:166-173.

16 Coogan PF, Rosenberg L. Impact of a financial incentive on case and control participation in a telephone interview. American Journal of Epidemiology 2004; 160:295-298.

17 Promislow JH, Makarushka CM, Gorman JR, Howards PP, Savitz DA, Hartmann KE. Recruitment for a communitybased study of early pregnancy: the Right from the Start study. Paediatric and Perinatal Epidemiology 2004; 18:143152

18 Michigan Department of Community Health. Vital Records and Health Data Development Section. Michigan 2006 Resident Birth files. http://www.mdch.state.mi.us/pha/ osr/CHI/Births/frame.html [last accessed 19 May 2009].

19 Sawyer SM, Cerritelli B, Carter LS, Cooke M, Glazner JA, Massie J. Changing their minds with time: a comparison of hypothetical and actual reproductive behaviors in parents of children with cystic fibrosis. Pediatrics 2006; 118:e649-e656.

20 Chen $\mathrm{CH}$, Chi CS. Maternal intention and actual behavior in infant feeding at one month postpartum. Acta Paediatrica Taiwanica 2003; 44:140-144. 